\title{
Astrocyte Elevated Gene-1 Increases Invasiveness of NSCLC Through Up-Regulating MMP7
}

\author{
Ren Zhu ${ }^{a, b}$ Ye Tian ${ }^{a}$ \\ aDepartment of Radiotherapy and Oncology, the Second Affiliated Hospital of Soochow University, \\ Suzhou, bDepartment of Oncology, Shanghai Pulmonary Hospital, Tongji University School of Medicine, \\ Shanghai, China
}

\section{Key Words}

Non-small cell lung cancer (NSCLC) - Matrix metalloproteinase 7 (MMP7) - ERK/MAPK signaling pathway • Astrocyte elevated gene-1 (AEG-1) • Metastases

\begin{abstract}
Background/Aims: The aggressive manner of non-small cell lung cancer (NSCLC) cells accounts for the majority of the lethality of the disease. Recently, increased astrocyte elevated gene-1 (AEG-1) levels have been shown to closely correlate with poor prognosis of NSCLC, whereas the underlying mechanisms are not clear. Methods: We examined the AEG-1 and matrix metalloproteinase 7 (MMP7) levels in NSCLC tissues, compared to the paired adjacent non-tumor lung tissue. We modulated AEG-1 levels in NSCLC cells, and examined its effects on MMP7 levels by RT-qPCR, on cellular protein by Western blot, and on secreted protein by ELISA. We also examined the cell invasiveness in AEG-1-modified NSCLC cells in a transwell cell migration assay. We used specific signal pathway inhibitors to treat AEG-1-modified NSCLC cells and examined its effects on MMP7. Results: AEG-1 and MMP7 levels were both significantly increased in NSCLC tissues, compared to the paired adjacent non-tumor lung tissue. The AEG-1 and MMP7 levels were strongly correlated. Overexpression of AEG-1 in NSCLC cells significantly increased MMP7 levels and cell invasiveness, while AEG-1 depletion in NSCLC cells significantly decreased MMP7 levels and cell invasiveness. Application of a specific MAPK-p42/p44 inhibitor, but not application of specific inhibitors for MAPK-p38, PI3k/Akt, or JNK signaling pathways, to AEG-1-overexpressing NSCLC cells substantially abolished the AEG-1-mediated MMP7 up regulation. Conclusion: AEG-1 promotes NSCLC cell invasiveness through MAPK-p42/p44-dependent activation of MMP7.
\end{abstract}




\section{Cellular Physiology Cell Physiol Biochem 2015;37:1187-1195 \begin{tabular}{ll|l} 
and Biochemistry Published online: September 29, 2015 & $\begin{array}{l}\text { (c) } 2015 \text { The Author(s). Published by S. Karger AG, Basel } \\
\text { www.karger.com/cpb }\end{array}$ \\
\hline
\end{tabular} \\ Zhu/Tian: AEG-1 Regulates MMP7 in NSCLC}

\section{Introduction}

Any type of epithelial lung cancer other than small cell lung cancer (SCLC) is classified as non-small cell lung cancer (NSCLC), which is consisted of adenocarcinoma, squamous cell carcinoma and large cell carcinoma. NSCLCs are generally insensitive to chemotherapy and radiation therapy, and are often not resectable at the time of diagnosis, largely due to its high invasiveness and predisposition to metastases. Multiple cell types, soluble growth factors and adhesion molecules are involved in the complex processes of cancer metastases [1-4]. However, our present knowledge on the molecular regulation of NSCLC cell invasiveness and metastases is incomplete [5-12]. Hence, further exploration of the molecular mechanisms underlying NSCLC invasiveness and metastases appears to be extremely important.

Primary human fetal astrocytes have been shown to upregulate astrocyte elevated gene1 (AEG-1) during HIV-1 infection. Moreover, the upregulation of AEG-1 has been detected in several types of human cancer, including melanoma, glioblastoma, breast cancer, esophageal squamous cell carcinoma, prostate cancer, neuroblastoma and NSCLC [13-17]. These studies demonstrate a substantial role of AEG-1 during cancer development and progression. For example, the expression of AEG-1 has been shown to be induced by activation of the phosphatidylinositol 3-kinase (PI3K)/Akt signaling pathway through a direct binding of the downstream factor c-Myc to the AEG-1 promoter [18]. In addition, ectopic expression of AEG-1 could inhibit serum starvation-induced cancer cell apoptosis through PI3K/ Akt-signaling-dependent suppression of p53 and p21. Similarly, AEG-1 has been shown to contribute to the carcinogenesis of breast cancer via inhibiting FoxO1 [19]. Besides PI3k/ Akt signaling pathway, AEG-1 has also been shown to promote growth of prostate cancer via NF- $\kappa B$ pathway activation [20-22], hepatocellular carcinoma via Wnt/ $\beta$-catenin signaling pathway [23]. Recently, increased astrocyte elevated gene-1 (AEG-1) levels have been shown to closely correlate with poor prognosis of NSCLC [24], whereas the underlying mechanisms are not clear.

The matrix metalloproteinase (MMP) family members are involved in the breakdown of extracellular matrix in normal physiological processes, such as embryonic development, reproduction, and tissue remodeling, as well as in disease processes, such as arthritis and metastasis [25, 26]. MMP7 is a member of MMP family. MMP7 is an important matrix proteinase that is secreted by various cancer cells to break down extracellular matrix. Overexpression of MMP7 has been reported to facilitate metastatic spread of different cancer cells and appears to be an important molecule to directly promote cancer metastasis [27-32]. Nevertheless, whether MMP7 may be regulated by AEG-1 in NSCLC is not known.

Here, we showed that AEG-1 and MMP7 levels were both significantly increased in NSCLC tissues, compared to the paired adjacent non-tumor lung tissue. The AEG-1 and MMP7 levels were strongly correlated. Overexpression of AEG-1 in NSCLC cells significantly increased MMP7 levels and cell invasiveness, while AEG-1 depletion in NSCLC cells significantly decreased MMP7 levels and cell invasiveness. Application of a specific MAPK-p42/p44 inhibitor, but not application of specific inhibitors for MAPK-p38, PI3k/Akt, or JNK signaling pathways, to AEG-1-overexpressing NSCLC cells substantially abolished the AEG-1-mediated MMP7 up regulation.

\section{Materials and Methods}

\section{Patient specimen}

Resected cancer specimens from 30 NSCLC patients were obtained together with the matched tumoradjacent normal lung tissues (NT) from 2010 to 2014 at the Second Affiliated Hospital of Soochow University. All patients provided signed, informed consent for their tissues to be used for scientific research. Ethical approval for the current study was obtained from the Second Affiliated Hospital of Soochow University. All diagnoses were based on pathological and/or cytological evidence. The histological features of the specimens were evaluated by senior pathologists according to the World Health Organization classification 


\section{Cellular Physiology Cell Physiol Biochem 2015;37:1187-1195 and Biochemistry \begin{tabular}{l|l|l|} 
DOI: 10.1159/000430242 & $\begin{array}{l}\text { (c) } 2015 \text { The Author(s). Published by S. Karger AG, Basel } \\
\text { www karger.com/cpb }\end{array}$
\end{tabular} \\ Zhu/Tian: AEG-1 Regulates MMP7 in NSCLC}

criteria. Tissues were obtained prior to chemotherapy and radiotherapy and were immediately frozen and stored at $-70^{\circ} \mathrm{C}$ prior to Western blot.

\section{Cell lines and reagents}

A549 is a human NSCLC line purchased from American Type Culture Collection (ATCC, Rockville, MD, USA), and was cultured in Dulbecco's Modified Eagle's Medium (DMEM) supplemented with 20\% fetal bovine serum (FBS, Invitrogen, Carlsbad, CA, USA) and L-glutamine in a humidified chamber with $5 \% \mathrm{CO}_{2}$ at $37^{\circ} \mathrm{C}$. The A549 cell line was first developed in 1972 by Dr. Giard through the removal and culturing of cancerous lung tissue in the explanted tumor of 58-year-old Caucasian male [33]. Inhibitors PD98059 (used at a dose of $10 \mu \mathrm{g} / \mathrm{ml}$ ), SB203580 (used at a dose of $1 \mu \mathrm{g} / \mathrm{ml}$ ), LY294002 (used at a dose of $20 \mu \mathrm{g} / \mathrm{ml}$ ), and SP600125 (used at a dose of $10 \mu \mathrm{g} / \mathrm{ml}$ ) were all purchased from Sigma-Aldrich (St. Louis, MO, USA).

\section{Modification of AEG-1 levels in NSCLC cell lines}

AEG-1-modificated-plasmids were prepared using routine methods. Briefly, the NSCLC cells were transfected with a AEG-1-overexpressing plasmid (AEG-1), or a small short hairpin interfering RNA for AEG-1 (shAEG-1), or a control scrambled sequence (scr) as a control, as has been previously described [14]. These plasmids were transfected into cultured NSCLC cells using Lipofectamine 2000, according to the manufacturer's instructions (Invitrogen). The plasmids also contained a GFP reporter to allow determination of transfection efficiency, which was nearly $100 \%$ in the current study.

\section{Transwell cell migration assay}

$5 \times 10^{5}$ Cells were plated into the top side of polycarbonate transwell filter coated with Matrigel in the upper chamber of the BioCoatTM Invasion Chambers (BD, Bedford, MA, USA) and incubated at $37^{\circ} \mathrm{C}$ for 22 hours. The cells inside the upper chamber with cotton swabs were then removed. Migratory and invasive cells on the lower membrane surface were fixed, stained with hematoxylin, and counted for 10 random 100X fields per well. Cell counts are expressed as the mean number of cells per field of view. Five independent experiments were performed and the data are presented as mean \pm standard deviation (SD).

\section{ELISA assay}

The concentration of MMP7 in the conditioned media from cultured cells was determined by a MMP7 ELISA Kit (Raybio, Norcross, GA, USA). ELISAs were performed according to the instructions of the manufacturer. Briefly, the collected condition media were added to a well coated with MMP7 polyclonal antibody, and then immunosorbented by biotinylated monoclonal anti-human MMP7 antibody at room temperature for 2 hours. The color development catalyzed by horseradish peroxidase was terminated with $2.5 \mathrm{~mol} / \mathrm{l}$ sulfuric acid and the absorption was measured at $450 \mathrm{~nm}$. The protein concentration was determined by comparing the relative absorbance of the samples with the standards.

\section{Quantitative PCR (RT-qPCR)}

MiRNA and total RNA were extracted from lung specimen or from the cultured cells using RNeasy kit (Qiagen, Hilden, Germany). For cDNA synthesis, complementary DNA (cDNA) was randomly primed from $2 \mu \mathrm{g}$ of total RNA using the Omniscript reverse transcription kit (Qiagen). RT-qPCR was subsequently performed in triplicate with a 1:4 dilution of cDNA using the Quantitect SyBr green PCR system (Qiagen) on a Rotorgene 6000 series PCR machine. All primers were purchased from Qiagen. Data were collected and analyzed using $2^{-\Delta \Delta \mathrm{Ct}}$ method. Values of genes were first normalized against $\beta$-actin, and then compared to the experimental controls.

\section{Western blot}

For analysis of total protein, the protein was extracted from the lung specimens or from the cultured cells, and homogenized in RIPA lysis buffer (1\% NP40, 0.1\% SDS, $100 \mu \mathrm{g} / \mathrm{ml}$ phenylmethylsulfonyl fluoride, $0.5 \%$ sodium deoxycholate, in PBS) on ice. The supernatants were collected after centrifugation at 12000 $\times \mathrm{g}$ at $4^{\circ} \mathrm{C}$ for $20 \mathrm{~min}$. Protein concentration was determined using a BCA protein assay kit (Bio-rad, China), and whole lysates were mixed with $4 \times$ SDS loading buffer $(125 \mathrm{mmol} / \mathrm{l}$ Tris-HCl, 4\% SDS, 20\% glycerol, $100 \mathrm{mmol} / \mathrm{l}$ DTT, and $0.2 \%$ bromophenol blue) at a ratio of $1: 3$. Protein samples were heated at $100^{\circ} \mathrm{C}$ for $5 \mathrm{~min}$ and were separated on SDS-polyacrylamide gels. The separated proteins were then transferred to a 


\section{Cellular Physiology Cell Physiol Biochem 2015;37:1187-1195 \\ \begin{tabular}{ll|l} 
DOI: 10.1159/000430242 & O 2015 The Author(s). Published by S. Karger AG, Basel \\
and Biochemistry & Published online: September 29, 2015 www.karger.com/cpb \\
\cline { 2 - 3 }
\end{tabular} \\ Zhu/Tian: AEG-1 Regulates MMP7 in NSCLC}

PVDF membrane. The membrane blots were first probed with a primary antibody. After incubation with horseradish peroxidase-conjugated second antibody, autoradiograms were prepared using the enhanced chemiluminescent system to visualize the protein antigen. The signals were recorded using X-ray film. Primary antibodies for Western Blot are anti-AEG-1(Invitrogen), anti-MMP7 and $\beta$-actin (all from Cell Signaling, San Jose, CA, USA). $\beta$-actin was used as protein loading controls. Secondary antibody is HRPconjugated anti-rabbit (Jackson ImmunoResearch Labs, West Grove, PA, USA). Images shown in the figures were representative from 5 individuals. Densitometry of Western blots was quantified with NIH ImageJ software (Bethesda, MA, USA). The protein levels were first normalized to $\beta$-actin, and then normalized to experimental controls.

\section{Statistics}

All statistical analyses were carried out using the SPSS 18.0 statistical software package. All values in cell and animal studies are depicted as mean \pm standard deviation and are considered significant if $\mathrm{p}<$ 0.05. All data were statistically analyzed using one-way ANOVA with a Bonferroni correction, followed by Fisher' Exact Test for comparison of two groups. Bivariate correlations were calculated by Spearman's rank correlation coefficients.

\section{Results}

AEG-1 and MMP7 levels upregulate and correlate with each other in NSCLC specimens

First, we found that the AEG-1 levels significantly increased in the NSCLC specimens, compared to paired non-tumor lung tissue (NT, Fig. 1A). Since AEG-1 has been shown to regulate cancer cell invasion and metastases, and since MMPs are direct regulators of tumor invasiveness, we thus examined the levels of MMPs in NSCLC specimens and checked their correlation with AEG-1 levels. Among all MMPs that had been examined, we found that the levels of MMP7 significantly increased in NSCLC (Fig. 1B), and strongly correlated with AEG1 levels in these NSCLC specimens (Fig. $1 \mathrm{C}, \mathrm{R}=0.72, \mathrm{p}<0.0001, \mathrm{~N}=30$ ). These data suggest a possible regulatory relationship between AEG-1 and MMP7 in NSCLC cells.

Fig. 1. AEG-1 and MMP7 levels upregulate and correlate with each other in NSCLC specimens. (A) AEG-1 levels significantly increased in the NSCLC specimens, compared to paired non-tumor lung tissue (NT), by Western blot. (B) MMP7 levels significantly increased in NSCLC specimens, compared to NT, by Western blot. (C) A strong positive correlation was detected between AEG-1 and MMP7 levels in NSCLC specimens $(\mathrm{R}=0.72, \mathrm{p}<0.0001$, $\mathrm{N}=30$ ). $* \mathrm{p}<0.05$.

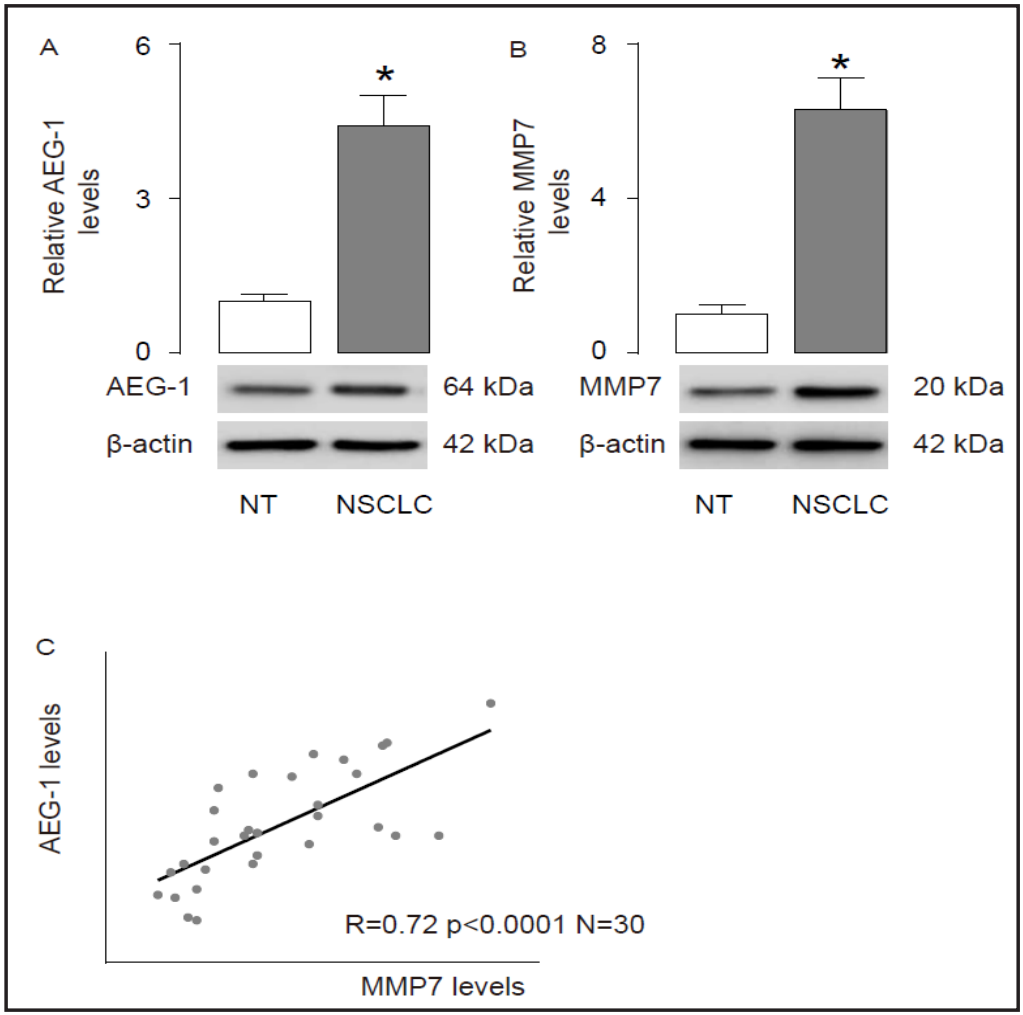




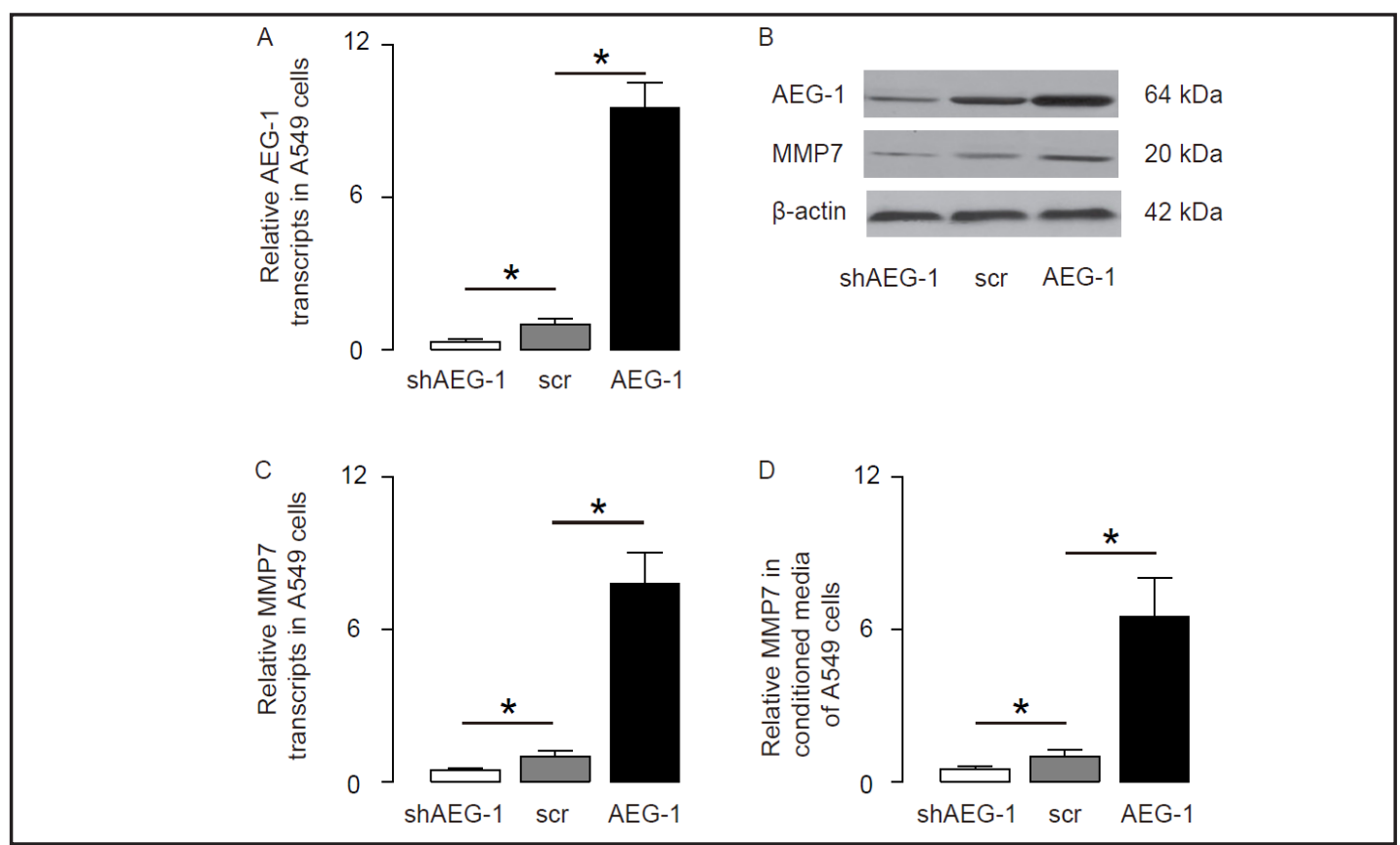

Fig. 2. AEG-1 increases MMP7 levels in NSCLC cells. We transfected the A549 cells with either an AEG-1 overexpressing plasmid (AEG-1), or a small short hairpin interfering RNA for AEG-1 (shAEG-1). The A549 cells were transfected with a scrambled sequence as a control (scr). (A) The AEG-1 levels by mRNA. (B) The AEG-1 and MMP7 levels by Western blot for cellular protein. (C) The MMP7 levels by mRNA. (D) The MMP7 levels by ELISA for the secreted protein in the conditioned media. ${ }^{*} \mathrm{p}<0.05, \mathrm{~N}=5$.

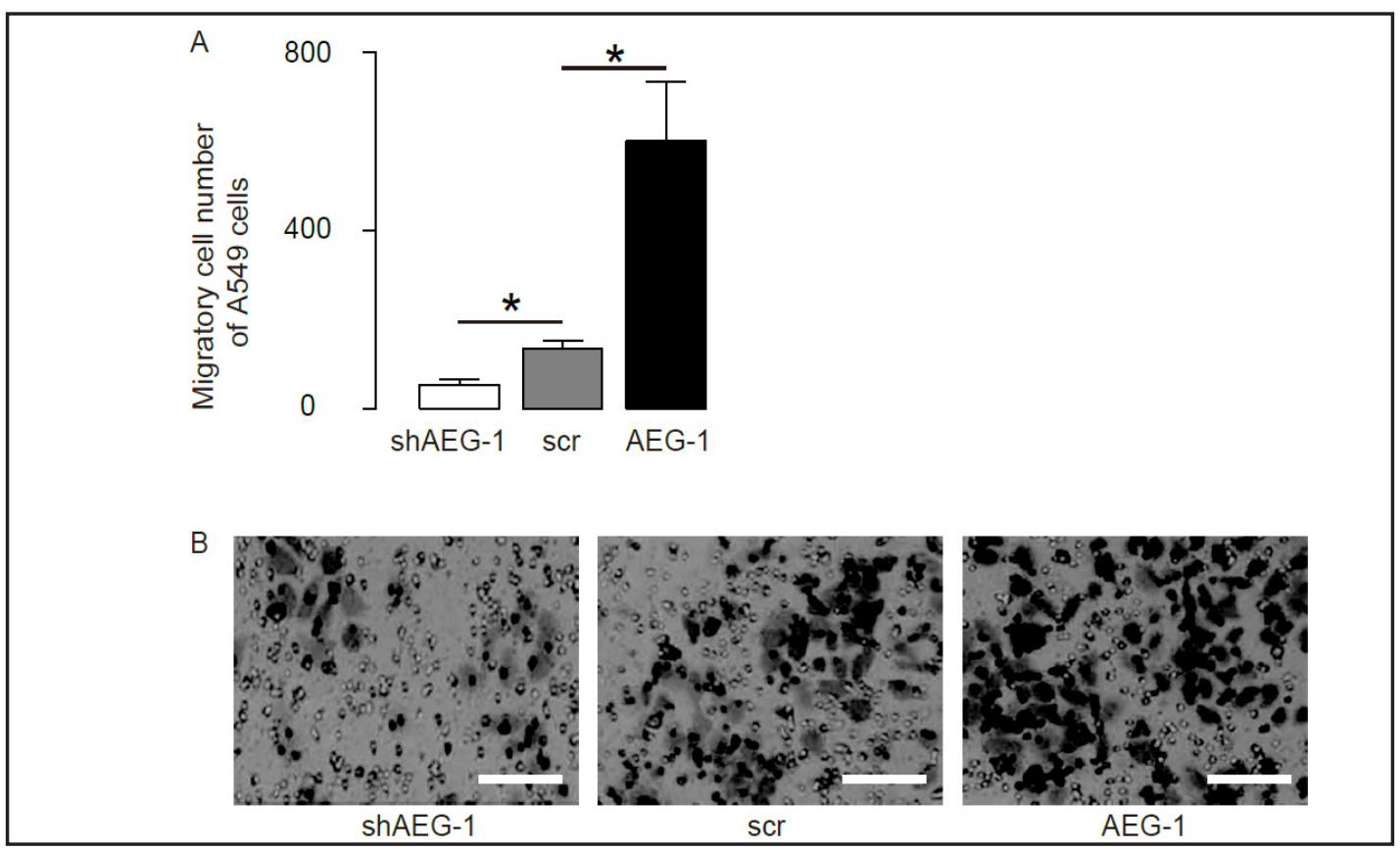

Fig. 3. AEG-1 enhances cell invasion in NSCLC cells. (A-B) Cell invasiveness of AEG-1-modified cells was examined in a transwell cell migration assay, shown by quantification (A), and by representative images (B). $* \mathrm{p}<0.05 . \mathrm{N}=5$.

AEG-1 increases MMP7 levels in NSCLC cells

Then we used a human NSCLC cell line, A549, to examine whether AEG-1 may regulate MMP7 levels. We transfected the A549 cells with either an AEG-1 overexpressing plasmid KARGER 


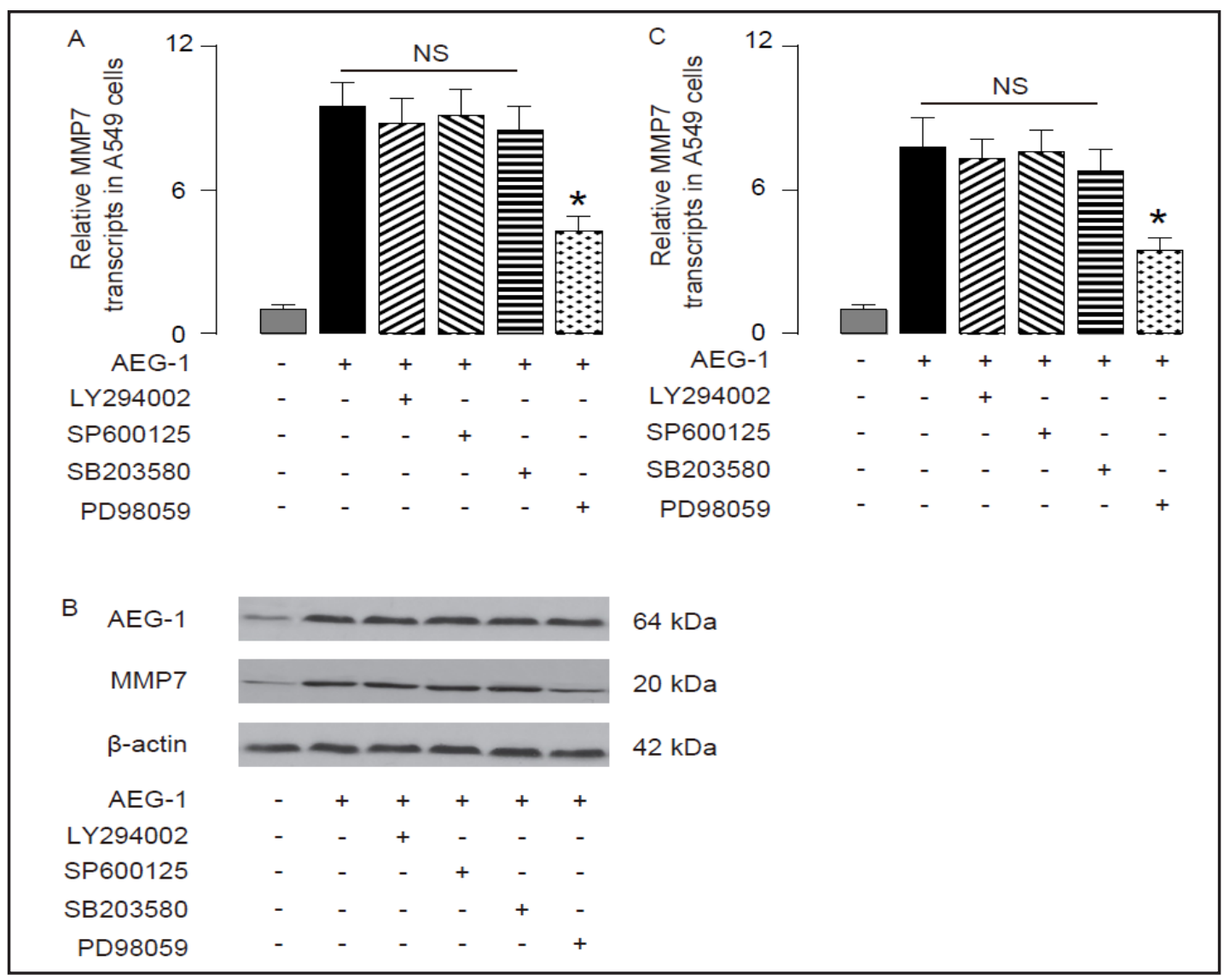

Fig. 4. AEG-1 activates MMP7 via MAPK-p24/p44 signaling pathway. (A-C) We then analyzed the signaling pathway through which AEG-1 activates MMP7. Application of a specific MAPK-p42/p44 signaling pathway inhibitor, PD98059 $(10 \mu \mathrm{g} / \mathrm{ml})$, but not application of either a specific MAPK-p38 signaling pathway inhi-

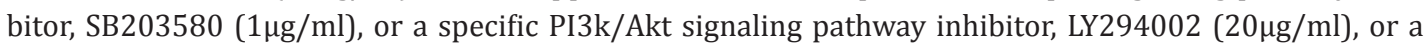
specific JNK pathway inhibitor, SP600125 (10 $\mathrm{gg} / \mathrm{ml})$, to AEG-1-overexpressing A549 cells substantially abolished the effect of AEG-1 on MMP7 activation, by mRNA (A), by Western blot for cellular protein (B), or by ELISA for secreted protein in the conditioned media (C). ${ }^{*} \mathrm{p}<0.05, \mathrm{~N}=5$. NS: non-significant.

(AEG-1), or a small short hairpin interfering RNA for AEG-1 (shAEG-1). The A549 cells were transfected with a scrambled sequence as a control (scr). First, we confirmed the modulation of AEG-1 levels in these cells by mRNA (Fig. 2A), and by Western blot for cellular protein (Fig. 2B). We found that overexpression of AEG-1 in A549 cells increased MMP7 levels, while inhibition of AEG-1 in A549 cells decreased MMP7 levels, by mRNA (Fig. 2C), by Western blot for cellular protein (Fig. 2B), and by ELISA for the secreted protein in the conditioned media (Fig. 2D). These data suggest that AEG-1 induces MMP7 production in NSCLC cells.

\section{AEG-1 enhances cell invasion in NSCLC cells}

Next, we examined whether the effects of AEG-1 on MMP7 may result in changes in cell invasiveness. We found that AEG-1 overexpression significantly increased the invasiveness of A549 cells, while inhibition of AEG-1 in A549 cells significantly decreased the invasiveness of A549 cells in a transwell matrix penetration assay, shown by quantification (Fig. 3A), and by representative images (Fig. 3B). Thus, AEG-1 enhances cell invasion in NSCLC cells.

\section{AEG-1 activates MMP7 via MAPK-p24/p44 signaling pathway}

We then analyzed the signaling pathway through which AEG-1 activates MMP7. Application of a specific MAPK-p42/p44 signaling pathway inhibitor, PD98059 (10 $\mu \mathrm{g} / \mathrm{ml})$, but 


\section{Cellular Physiology Cell Physiol Biochem 2015;37:1187-1195 \begin{tabular}{ll|l} 
DOI: 10.1159/000430242 & O 2015 The Author(s). Published by S. Karger AG, Basel \\
and Biochemistry & $\begin{array}{l}\text { Published online: September 29, } 2015 \\
\text { www.karger.com/cpb }\end{array}$ \\
\cline { 2 - 3 }
\end{tabular} \\ Zhu/Tian: AEG-1 Regulates MMP7 in NSCLC}

not application of either a specific MAPK-p38 signaling pathway inhibitor, SB203580 (1 $\mu \mathrm{g} / \mathrm{ml}$ ), or a specific PI3k/Akt signaling pathway inhibitor, LY294002 $(20 \mu \mathrm{g} / \mathrm{ml})$, or a specific JNK pathway inhibitor, SP600125 $(10 \mu \mathrm{g} / \mathrm{ml})$, to AEG-1-overexpressing A549 cells substantially abolished the effect of AEG-1 on MMP7 activation, by mRNA (Fig. $4 \mathrm{~A}$ ), by Western blot for cellular protein (Fig. 4B), or by ELISA for secreted protein in the conditioned media (Fig. 4C). These data suggest that AEG-1 may activate MMP7 via MAPK-p42/p44 signaling pathway (Fig. 5).
Fig. 5. A schematic model. AEG-1 activates MMP7-mediated cell invasion via MAPK-p42/ p44 signaling pacells. thway in NSCLC

\section{Discussion}

Understanding the molecular basis on the cancer metastasis may substantially improve the prevention and treatment of NSCLC. All the events that relate to cancer cell outgrowth, invasion and migration are critical for cancer metastases [1]. MMP7 is a member of MMP family, and plays a critical role in the processes of cancer metastases in different types of cancer, including NSCLC. AEG-1 is a newly defined oncogene in many cancers and seems to regulate cancer initiation, growth and metastases [13-17]. Nevertheless, whether AEG-1 may regulate MMP7-mediated cancer cell invasion has not been examined in NSCLC cells.

Here we found strong correlation of AEG-1 and MMP7 levels in the NSCLC specimens, and both were significantly upregulated. These data suggest a possible relationship between AEG-1 and MMP7 in NSCLC cells. To prove this hypothesis, we used several human NSCLC cell lines, e.g. A549, H460, to examine the interaction of AEG-1 and MMP7. Since we got similar results, only data from A549 cells were shown here. We found that overexpression of AEG-1 in A549 cells increased expression of MMP7, while inhibition of AEG-1 in A549 cells decreased expression of MMP7. These data suggest that AEG-1 may function upstream of MMP7 and acts as a regulator of MMP7 in NSCLC cells. We then analyzed how AEG-1 may affect the expression of MMP7. Application of a specific MAPK-p42/p44 inhibitor to AEG-1-overexpressing A549 cells substantially abolished the effect of AEG-1 on MMP7 activation. Of note, the application of this inhibitor did not alter the AEG-1 levels in the AEG1-overexpressing A549 cells. Thus, AEG-1 may increase expression of MMP7 via MAPK-p42/ p44 signaling pathway. Based on literature, it seemed that MMPs did not affect AEG-1 [14]. We have transfected the A549 cells with MMP7 or shMMP7 plasmids and we did not see changes in AEG-1 levels.

Anti-AEG-1 was recently applied in the clinical trials targeting cancer-related angiogenesis, but the mechanism has been regarded as inhibition of endothelial growth and capillary permeability in the cancer tissue. Now our data suggest that anti-AEG-1 may also decrease MMP7 expression to impair the extracellular matrix degradation, at least in NSCLC cells.

Our study thus illustrates a novel model for the control of the invasiveness of NSCLC cells. Further delineation of the precise molecular mechanisms underlying the regulation of MMP7 by AEG-1 may substantially improve our understanding of the metastases of NSCLC and provide novel therapeutic targets for lung cancer.

\section{Disclosure Statement}

The authors have declared that no competing interests exist. 


\section{Cellular Physiology Cell Physiol Biochem 2015;37:1187-1195

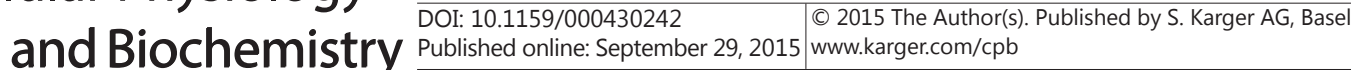 \\ Zhu/Tian: AEG-1 Regulates MMP7 in NSCLC}

\section{References}

1 Joyce JA, Pollard JW: Microenvironmental regulation of metastasis. Nat Rev Cancer 2009;9:239-252.

2 Zhang L, Qian J, Qiang Y, Huang H, Wang C, Li D, Xu B: Down-regulation of mir-4500 promoted non-small cell lung cancer growth. Cell Physiol Biochem 2014;34:1166-1174.

3 Tian Z, Yao G, Song H, Zhou Y, Geng J: Igf2r expression is associated with the chemotherapy response and prognosis of patients with advanced nsclc. Cell Physiol Biochem 2014;34:1578-1588.

4 Yun M, Kim EO, Lee D, Kim JH, Kim J, Lee H, Lee J, Kim SH: Melatonin sensitizes h1975 non-small-cell lung cancer cells harboring a t790m-targeted epidermal growth factor receptor mutation to the tyrosine kinase inhibitor gefitinib. Cell Physiol Biochem 2014;34:865-872.

5 Ji Y, Gao F, Sun B, Hao J, Liu Z: Angiotensin-converting enzyme 2 inhibits apoptosis of pulmonary endothelial cells during acute lung injury through suppressing smad2 phosphorylation. Cell Physiol Biochem 2015;35:2203-2212.

6 Jian H, Zhao Y, Liu B, Lu S: Sema4b inhibits growth of non-small cell lung cancer in vitro and in vivo. Cell Signal 2015;27:1208-1213.

7 Jian H, Zhao Y, Liu B, Lu S: Sema4b inhibits mmp9 to prevent metastasis of non-small cell lung cancer. Tumour Biol 2014;35:11051-11056.

8 Pei J, Lou Y, Zhong R, Han B: Mmp9 activation triggered by epidermal growth factor induced foxo1 nuclear exclusion in non-small cell lung cancer. Tumour Biol 2014;35:6673-6678.

9 Tang Q, Zhao S, Wu J, Zheng F, Yang L, Hu J, Hann SS: Inhibition of integrin-linked kinase expression by emodin through crosstalk of ampkalpha and erk1/2 signaling and reciprocal interplay of sp1 and c-jun. Cell Signal 2015;27:1469-1477.

10 Hahn SS, Tang Q, Zheng F, Zhao S, Wu J: Gw1929 inhibits alpha7 nachr expression through ppargammaindependent activation of 38 mapk and inactivation of pi3-k/mtor: The role of egr- 1 . Cell Signal 2014;26:730-739.

11 Zhao L, Wang DL, Liu Y, Chen S, Sun FL: Histone acetyltransferase hmof promotes s phase entry and tumorigenesis in lung cancer. Cell Signal 2013;25:1689-1698.

12 Hu X, Zhang F, Liu XR, Wu YT, Ni YM: Efficacy and potential microrna mechanism for computed tomography-guided percutaneous radiofrequency ablation of primary lung cancer and lung metastasis from liver cancer. Cell Physiol Biochem 2014;33:1261-1271.

13 Dong L, Qin S, Li Y, Zhao L, Dong S, Wang Y, Zhang C, Han S: High expression of astrocyte elevated gene-1 is associated with clinical staging, metastasis, and unfavorable prognosis in gastric carcinoma. Tumour Biol 2015;36:2169-2178.

14 Song H, Tian Z, Qin Y, Yao G, Fu S, Geng J: Astrocyte elevated gene-1 activates mmp9 to increase invasiveness of colorectal cancer. Tumour Biol 2014;35:6679-6685.

15 Zheng J, Li C, Wu X, Liu M, Sun X, Yang Y, Hao M, Sheng S, Sun Y, Zhang H, Long J, Liang Y, Hu C: Astrocyte elevated gene-1 (aeg-1) shrna sensitizes huaier polysaccharide (hp)-induced anti-metastatic potency via inactivating downstream p13k/akt pathway as well as augmenting cell-mediated immune response. Tumour Biol 2014;35:4219-4224.

16 Li C, Chen K, Cai J, Shi QT, Li Y, Li L, Song H, Qiu H, Qin Y, Geng JS: Astrocyte elevated gene-1: A novel independent prognostic biomarker for metastatic ovarian tumors. Tumour Biol 2014;35:3079-3085.

17 Zheng J, Li C, Wu X, Yang Y, Hao M, Sheng S, Sun Y, Zhang H, Long J, Hu C: Astrocyte elevated gene-1 is a novel biomarker of epithelial-mesenchymal transition and progression of hepatocellular carcinoma in two china regions. Tumour Biol 2014;35:2265-2269.

18 Lee SG, Su ZZ, Emdad L, Sarkar D, Fisher PB: Astrocyte elevated gene-1 (aeg-1) is a target gene of oncogenic ha-ras requiring phosphatidylinositol 3-kinase and c-myc. Proc Natl Acad Sci U S A 2006;103:1739017395.

19 Li J, Yang L, Song L, Xiong H, Wang L, Yan X, Yuan J, Wu J, Li M: Astrocyte elevated gene-1 is a proliferation promoter in breast cancer via suppressing transcriptional factor foxo1. Oncogene 2009;28:3188-3196.

20 Kikuno N, Shiina H, Urakami S, Kawamoto K, Hirata H, Tanaka Y, Place RF, Pookot D, Majid S, Igawa M, Dahiya R: Knockdown of astrocyte-elevated gene-1 inhibits prostate cancer progression through upregulation of foxo3a activity. Oncogene 2007;26:7647-7655.

21 Sarkar D, Park ES, Emdad L, Lee SG, Su ZZ, Fisher PB: Molecular basis of nuclear factor-kappab activation by astrocyte elevated gene-1. Cancer Res 2008;68:1478-1484. 


\section{Cellular Physiology Cell Physiol Biochem 2015;37:1187-1195 \begin{tabular}{ll|l} 
DOI: 10.1159/000430242 & O 2015 The Author(s). Published by S. Karger AG, Basel \\
and Biochemistry & Published online: September 29, 2015 wwwkkarger.com/cpb
\end{tabular} \\ Zhu/Tian: AEG-1 Regulates MMP7 in NSCLC}

22 Emdad L, Sarkar D, Su ZZ, Randolph A, Boukerche H, Valerie K, Fisher PB: Activation of the nuclear factor kappab pathway by astrocyte elevated gene-1: Implications for tumor progression and metastasis. Cancer Res 2006;66:1509-1516.

23 Yoo BK, Emdad L, Su ZZ, Villanueva A, Chiang DY, Mukhopadhyay ND, Mills AS, Waxman S, Fisher RA, Llovet JM, Fisher PB, Sarkar D: Astrocyte elevated gene-1 regulates hepatocellular carcinoma development and progression. J Clin Invest 2009;119:465-477.

24 Sun S, Ke Z, Wang F, Li S, Chen W, Han A, Wang Z, Shi H, Wang LT, Chen X: Overexpression of astrocyteelevated gene-1 is closely correlated with poor prognosis in human non-small cell lung cancer and mediates its metastasis through up-regulation of matrix metalloproteinase-9 expression. Hum Pathol 2012;43:1051-1060.

25 Davidson B, Reich R, Risberg B, Nesland JM: The biological role and regulation of matrix metalloproteinases (mmp) in cancer. Arkh Patol 2002;64:47-53.

26 Rhee JS, Coussens LM: Recking mmp function: Implications for cancer development. Trends Cell Biol 2002;12:209-211.

27 Ding H, Zhu Y, Chu T, Wang S: Epidermal growth factor induces foxo1 nuclear exclusion to activate mmp7mediated metastasis of larynx carcinoma. Tumour Biol 2014;35:9987-9992.

28 Jiang Y, Sun S, Liu G, Yan B, Niu J: Nrdp1 inhibits metastasis of colorectal cancer cells by egfr signalingdependent mmp7 modulation. Tumour Biol 2015;36:1129-1133.

29 Liu G, Jiang C, Li D, Wang R, Wang W: Mirna-34a inhibits egfr-signaling-dependent mmp7 activation in gastric cancer. Tumour Biol 2014;35:9801-9806.

30 Wang J, Su H, Han X, Xu K: Inhibition of fibroblast growth factor receptor signaling impairs metastasis of hepatocellular carcinoma. Tumour Biol 2014;35:11005-11011.

31 Ye Y, Zhou X, Li X, Tang Y, Sun Y, Fang J: Inhibition of epidermal growth factor receptor signaling prohibits metastasis of gastric cancer via downregulation of mmp7 and mmp13. Tumour Biol 2014;35:1089110896.

32 Zhang J, Wang S, Lu L, Wei G: Mir99a modulates mmp7 and mmp13 to regulate invasiveness of kaposi's sarcoma. Tumour Biol 2014;35:12567-12573.

33 Giard DJ, Aaronson SA, Todaro GJ, Arnstein P, Kersey JH, Dosik H, Parks WP: In vitro cultivation of human tumors: Establishment of cell lines derived from a series of solid tumors. J Natl Cancer Inst 1973;51:14171423. 